\title{
Effects of Habitual Low-Impact Dance on the Balance and Torque of the Knees of Older Female Individuals
}

\author{
Huiying $\mathrm{Wu}^{1}$, Jungsheng $\mathrm{Gau}^{2}$, Chin Hsing $\mathrm{Hsu}^{1}$, Jui Hung $\mathrm{Tu}^{3}$, Te Hung $\mathrm{Tsao}^{4}$ \\ ${ }^{1}$ Department of Recreation Sport and Health Promotion, \\ National Pingtung University of Science \& Technology, Pingtung, Chinese Taipei \\ ${ }^{2}$ Office of Physical Education, Chang Gung University of Science and Technology, Tauyau, Chinese Taipei \\ ${ }^{3}$ Department of Physical Education, National Pingtung University of Education, Pingtung, Chinese Taipei \\ ${ }^{4}$ Physical Education Section of General Education, National Sun Yat-sen University, Kaohsiung, Chinese Taipei \\ Email: t1208t2001@gmail.com, thtsao@mail.nsysu.edu.tw
}

Received March 22 ${ }^{\text {nd }}, 2012$; revised April 18 ${ }^{\text {th }}$, 2012; accepted May 2 ${ }^{\text {nd }}, 2012$

\begin{abstract}
Backgroud: Despite of many people engaging in aerobic dance activities, little knowledge was reported regarding the effects of low-impact dance on the balance, torque and range of motion (ROM) of joints of the lower extremities. Thus, the aim of this study was to examine whether any differences existed in terms of the aforementioned variables between older females who regularly engaged in low-impact dance and those who were physically inactive. Method: In total, 38 older females comprised the subjects of this study, which consisted of a dance group (DG) and a control group (CG). The extension torque of the knees, dynamic and static balance, and ROMs of the hip and ankles of all participants were measured. Results: Dynamic balance in the DG was significantly higher than that in the CG $(13.0 \pm 4.7$ vs. $5.5 \pm 7.8$ times, $p<0.05$ ). Although the knee extension torque for both legs was higher in the DG than in the CG, a significant difference was only found in the non-dominant leg. A few ROMs of lower-extremities joints in the dominant leg, ankle inversion, plantiflexion and dorsiflexion were significantly higher in the DG than the CG $(p<0.05)$. In addition, ankle inversion of the non-dominant leg in the DG was also significantly higher than that in the CG. Conclusions: Compared to their physically inactive counterparts, older females who habitually engage in low-impact dance had significantly higher dynamic balance, knee extension in the non-dominant leg, and ROMs of several joints of the lower extremities. Although this research was not an intervention study, these positive results should encourage further studies, because the aforementioned parameters are associated with risk factors for and reductions in falls.
\end{abstract}

Keywords: Low-Impact Dance; Fall; Balance; Knee Joint Torque

\section{Introduction}

Similar to many countries worldwide, the aging population (over 65 years) is increasing, and a "silver society" seems to be an unavoidable trend in Taiwan. The aging population is estimated to be $10 \%$ of the population in Taiwan. Negative phenomena with respect to physiology and psychology, such as weak muscular strength, a decline in the balance capacity, slower metabolism, and depression, become more prevalent in aging individuals. Everyone alive will face the aging phenomenon; however, these negative influences of aging can be somewhat attenuated through regular physical activities and exercise (American College of Sports Medicine (ACSM), 1998; Steffen et al., 2002). As a result, the American Collage of Sports Medicine (ACSM) and American Heart Association (AHA) jointly recommend that older adults under 65 years of age need a minimum of $30 \mathrm{~min}$ of moderate-intensity aerobic physical activity 5 days a week or a minimum of 20 min of vigorous-intensity aerobic activity 3 days a week to promote and maintain health (Haskell et al., 2007).

Although the majority of exercises are beneficial for mental and physical health, extra attention should be paid to older adults engaged in physical activities, especially older women. The reason is that they are close to or in the period of menopause (Asikainen et al., 2004; Roberts, 2007). Due to loss of estrogen during menopause, a declines in balance and muscle strength in female adults might be faster compared to premenopausal women. Menopause is associated with loss of estrogen (Greeves et al., 1999; Hammar et al., 1996). Loss of balance and weak strength in the lower extremities are risk factors for falls in older individuals (Rubenstein, 2006; Yokoya et al., 2008). As a result, in addition to improving those negative phenomena by hormone replacement therapy (Carville et al., 2006; Götherström et al., 2010), interventions with of a battery of physical activities or exercises are effective in reducing of fall risk factors and fall cases (Bocalini et al., 2009; Shigematsu et al., 2008).

Among a variety of physical activities, aerobic dance is one of the recommended physical activities and is widely enjoyed by women. Although aerobic dance can enhance and improve cardiorespiratory fitness, the maximal oxygen capability, and submaximal aerobic power of older adults (Dowdy et al., 1985), higher peak impact forces, higher mean loading rate, and a higher mean impact impulse with aerobic dance pose potential risks to the strength, joints, and soft tissues of the lower extremities of participants (Ricard \& Veatch, 1990; Janis, 1990). As a result, older or sedentary women who wish to engage in this activity should carefully consider the risks. On the other hand, several studies (Hopkins et al., 1990; Shimamoto et al., 1998) reported that low-impact dance can improve cardiopulmonary fitness, and muscular strength and endurance. In addition to lower-impact 
forces on the lower extremities with low-impact dance, an obvious difference between low- and high-impact dance is that with low-impact aerobic dance, one foot maintains contact with the floor at all times, which differs from both feet sometimes synchronously leaving the ground in high-impact dance (Ricard \& Veatch, 1990). Consequently, as long as the influences of impact on the lower extremities is considered, the characteristics of low-impact dance seem to be more appropriate for those who are weak strength in the lower extremities or sedentary when they begin an exercise program. Despite the benefits ascertained in previous studies and seemingly positive features from our assumptions, there are few studies of the effects of low-impact dance on balance, torque, and ROM of joints of the lower extremities. However, those parameters are significantly related to risk factors for falling. As a result, the aim of this study was to investigate the effects of low-impact dance on balance and knee torque in participants and to compare the above-mentioned parameters with those of a physically inactive cohort. In addition, the ROM of several joints in the lower extremities, such as the hip and ankles, were also measured and analyzed in this study. We hypothesized that these parameters in women who engage in regular low-impact dance would significantly differ compared to those of their physically inactive counterparts.

\section{Methods}

\section{Participants}

The design of this research was a comparative of cross-sectional study. The age range of participating females in this study was 50 - 70 years. All female participants were screened by a physician to ensure that they had no cardiovascular, metabolic, or pulmonary diseases. In addition, individuals who had such problems or diseases related to the musculoskeletal system and had taken any hormone-related medicine for menopause within 6 months before the study were excluded. Individuals who had engaged in low-impact aerobic dance for at least 3 years, 30 min each time, five times per week were included in the dance group (DG). These conditions with respect to regular physical activity matched recommendations of the ACSM (Haskell et al., 2007). On the other hand, individuals who did not exceed 20 min of structured physical activity at most in a week and those who did not engage in physical labor in their occupations were included in the control group (CG). Originally, numbers of individuals with the intention of participating in this research were 33 in the DG and 19 in the CG, respectively. After screening all of these potential persons for their regular low-impact dance habits and health conditions in the DG and whether they had engaged in regular exercise or physical activity within the last 6 months in the CG, 26 low-impact dancers in the DG and 12 individuals in the CG matched the conditions of the study. However, those who were not subjects in this study did not differ from participants in age or BMI. All eligible subjects provided written informed consent before they were allowed to participate in the study. According to the instructor's records, the compliance rate for low-impact dance participants exceeded 85\% in each month. Approval for this study was obtained from the Human Subject Internal Review Board of the local hospital. All measurements in the present study were conducted in a sports biomechanics laboratory.

\section{Participants' Anthropometric Measurements}

The height and weight of all participants were measured with an electronic stadiometer (Seca, Model 242, Hanover, MD) and digital scale (Tanita, Model BWB-627A, Hong Kong, China), respectively. The BMI was calculated by dividing the weight (kg) by the height $(\mathrm{m})$ squared $\left(\mathrm{kg} / \mathrm{m}^{2}\right)$. In addition, the percent body fat was measured by InBody 720 (BIOSPACE, Seoul, South Korea). The measurement was carried out in the morning after an overnight fast.

\section{The Program of Low-Impact Aerobic Dance}

The general program of low-impact dance consisted of three parts: warming up, reviewing actions in the previous sessions and practicing all of the actions with the music, and teaching new actions. Of these, reviewing and practicing occupied the most time in a given program. The main exercises for the lower extremities were side-stepping, walking forward and backward, circling, lifting the legs, tiptoeing with the foot to the front, side, and rear, and heel rises. The main exercises for the upper extremities were stretching, circling, shrugging, abduction, adduction, and circumduction.

\section{Balance}

The balance measurement was divided into two parts: dynamic and static balance. The former was measured with a stabilometer (Model 1630, Lafayette Instrument Inc., IN). A participant stood on the stabilometer with a fixed width between the medial borders of the feet, and balance was determined by maintaining one's position within $\pm 5^{\circ}$ relative to the horizontal plane. The balance times in $30 \mathrm{~s}$ were calculated and recorded by the program of the stabilometer. Static balance was measured by balancing on one leg with eyes closed. The time for this measurement was recorded from when one foot left the ground to when the person touched a support (wall, chair, or protectors). The time interval between measurements on the two legs was $1 \mathrm{~min}$.

\section{Knee-Joint Extension Torque Test}

The mean peak torque for each knee extension of all participants was determined by averaging peak torque values from three maximal trials with an intervening 2-min rest period between trials. Subjects were tightly secured to a fixed chair using waist, chest, and thigh straps. The knee was positioned in $120^{\circ}$ of flexion and the hip in $90^{\circ}$ flexion. The lateral condyle of the tibia was aligned with the axis of the torque sensor. The force measurement device can measure the force generated by the knee extension using a torque sensor (Jihsense RT-100, Taipei, Taiwan). When the knee torque measurement of one leg was completed, the assessment for the other leg began after a 3-min rest period. This torque instrument was calibrated according to the manufacturer's instructions before the measurement. The inter- and intra-individual coefficients of variation for all variables in this study were $<7 \%$.

\section{ROM of the Hip and Ankle Joints}

Parameters related to the lower extremities in the current study were separately analyzed for the dominant and non-dominant legs in order to examine differences between legs for those who were habitual low-impact dancers because some actions, for example, being supported by a single leg, circling, and stepping to the side, might subconsciously be executed using the dominant leg. To identify the dominant leg, we asked participants 
with which leg they preferred to kick a ball (Ricotti \& Ravaschio, 2011). Hip joint flexion, extension, internal rotation, and external rotation and ankle joint inversion, eversion, plantirflexion, and dorsiflexion ROMs of all participants were measured using a goniometer (NexGen Ergonomics, Quebec, Canada) by an experienced physiotherapist, who was blinded to the group categories. The methods of Norkin and White (1995) for hip and ankle joint ROMs were adopted in the current study. Before testing, participants were asked to warm up for 3 - 5 min. All values of ROM measured for these joints were obtained from the mean of two measurements. If the difference between these two measurements of any variable exceeded $2^{\circ}$, a third measurement was performed.

\section{Statistical Analysis}

Results of all parameters are expressed as the mean \pm standard deviation (SD). Variables in the two different groups were compared by an independent Student's $t$-test. All data analyses were performed with SPSS vers. 15.0 (SPSS, Chicago, IL, USA). The significance level was set to $p<0.05$.

\section{Results}

For the knee-extension torque, the sample size of 38 subjects was sufficient to give a statistical power of $80 \%$ with a signifycance level of $p<0.05$ after a statistical power analysis (G*Power 3.0, Franz Faul, Kiel University, Germany). The average number of days in a week in which participants engaged in low-impact dance in the DG group was $5.9 \pm 0.8$ days, which agreed with the physical activity recommendations of the ACSM for adults. The age, BMI, body fat percentage, and waist-to-hip ratio (WHR) of participants in these two groups are presented in Table 1. Participants in this study were categorized as being overweight according to the BMI value ( $>25)$. Although the BMI value and percentage of body fat were slightly higher in the CG than the DG, the results showed no significant differences between the two groups.

The balance times on the stabilometer were significantly higher in the DG than in the CG (Table 1), although no significant difference was detectable in static balance of either leg between the two groups (Table 2). For knee-extension torque, although this variable in the dominant (DG: $57.9 \pm 20.6$ vs. CG: $43.3 \pm 13.9$ Newton $[\mathrm{N}] \cdot \mathrm{m}, p=0.053$ ) and non-dominant legs (DG: $57.2 \pm 22.2$ vs. $40.3 \pm 16.5 \mathrm{~N} \cdot \mathrm{m}, p<0.05$ ) was higher in the DG than the CG, a significant difference was only found in the non-dominant leg between these two groups (Table 2).

The ROMs of the hip and ankle joints of participants in these two groups are given in Table 3 . The DG group had signifycantly higher values for inversion of the ankle than the CG for both the dominant and non-dominant legs $(p<0.05)$. In addition, ankle plantiflexion and dorsiflexion in the dominant leg were significantly higher in the DG than the CG $(p<0.05)$. For ROMs of the hip, hip extension in both legs of the DG was significantly higher than that of the CG. However, the hip external rotation of the non-dominant leg in the CG was significantly higher than that in the DG.

\section{Discussion}

Although previous studies on aerobic dance indicated that both low- and high-impact aerobic dancing were beneficial for cardiorespiratory fitness (CRF) of overweight females (Dodwy et al., 1985; Shimamoto et al., 1998), data on the balance, torque, and ROM of joints of the lower extremities from low-impact

Table 1.

Participant's characteristics and dynamic balance between the Dance Group (DG) and Control Group (CG).

\begin{tabular}{ccc}
\hline & DG $(n=26)$ & CG $(n=12)$ \\
\hline Age (year) & $59.1 \pm 8.3$ & $62.0 \pm 5.3$ \\
BMI $\left(\mathrm{kg} / \mathrm{m}^{2}\right)$ & $24.7 \pm 3.0$ & $25.9 \pm 3.0$ \\
Body fat percentage (\%) & $36.5 \pm 5.5$ & $37.8 \pm 5.2$ \\
Waist-to-hip ratio & $0.95 \pm 0.05$ & $0.97 \pm 0.03$ \\
Dynamic balance (times) & $13.0 \pm 14.7^{*}$ & $5.5 \pm 7.8$ \\
\hline
\end{tabular}

${ }^{*}$ significantly differs from the CG, $p<0.05$.

Table 2.

The static balance and knee extension torque in the Dance Group (DG) and Control Group (CG).

\begin{tabular}{lcccccc}
\hline \multirow{2}{*}{ Item } & \multicolumn{3}{c}{ Dominant leg } & \multicolumn{4}{c}{ Non-dominant leg } \\
\cline { 2 - 7 } & DG & CG & p & DG & CG & p \\
\hline $\begin{array}{l}\text { Single-leg } \\
\text { with eyes } \\
\text { closed (s) }\end{array}$ & $7.1 \pm 10.9$ & $7.4 \pm 4.8$ & 0.63 & $7.6 \pm 14.8$ & $7.1 \pm 6.1$ & 0.25 \\
$\begin{array}{c}\text { Torque } \\
\text { (N·m) }\end{array}$ & $57.9 \pm 20.6$ & $43.3 \pm 13.9$ & 0.053 & $57.2 \pm 22.2^{*}$ & $40.3 \pm 16.5$ & $<0.05$ \\
\hline significantly differs from the CG, $p<0.05$. & & & &
\end{tabular}

Table 3.

Characteristics of the study population and descriptive statistics.

\begin{tabular}{|c|c|c|c|c|c|c|}
\hline \multirow{2}{*}{ Item } & \multicolumn{3}{|c|}{ Dominant leg } & \multicolumn{3}{|c|}{ Non-dominant leg } \\
\hline & DG & CG & $p$ & DG & CG & $p$ \\
\hline Ankle inversion & $17.2 \pm 4.9^{*}$ & $8.3 \pm 4.6$ & $<0.01$ & $15.7 \pm 3.9^{*}$ & $8.6 \pm 2.6$ & $<0.01$ \\
\hline Ankle eversion & $12.9 \pm 5.0$ & $11.7 \pm 4.8$ & 0.89 & $13.6 \pm 4.0$ & $11.6 \pm 2.7$ & 0.25 \\
\hline Ankle plantiflexion & $37.6 \pm 5.6^{*}$ & $33.2 \pm 5.2$ & 0.04 & $35.1 \pm 4.4$ & $34.8 \pm 7.4$ & 0.81 \\
\hline Ankle dorsiflexion & $18.3 \pm 5.0^{*}$ & $14.0 \pm 5.7$ & 0.03 & $17.1 \pm 5.0$ & $15.1 \pm 4.3$ & 0.52 \\
\hline Hip extension & $21.0 \pm 6.9^{*}$ & $15.0 \pm 3.3$ & $<0.05$ & $22.9 \pm 7.8^{*}$ & $14.0 \pm 3.9$ & $<0.05$ \\
\hline Hip flexion & $108.5 \pm 9.6$ & $104.0 \pm 17.61$ & 0.14 & $109.0 \pm 12.0$ & $107.5 \pm 19.5$ & 0.20 \\
\hline Hip internal rotation & $31.6 \pm 8.9$ & $34.6 \pm 5.5$ & 0.73 & $27.8 \pm 7.0$ & $28.0 \pm 7.0$ & 0.51 \\
\hline Hip external rotation & $30.6 \pm 7.6$ & $30.0 \pm 5.9$ & 0.19 & $31.9 \pm 6.4^{*}$ & $37.8 \pm 5.3$ & $<0.05$ \\
\hline
\end{tabular}


dance are scarce. Results of the current study support older females who habitually engage in low-impact dance having a higher dynamic balance capacity, greater knee extension torque, and larger ROMs of most of the lower-extremities joints compared to those who are physically inactive.

Longitudinal and cross-sectional studies reported that maintenance or interventions with physical activities or exercise that enhance muscle strength and balance in older individuals (Bird et al., 2009; Chandler et al., 1998; Hortobágyi et al., 2001), even exercises of low intensity such as walking, cycling, and tai chi (Huang et al., 2011; Macaluso et al., 2003; Melzer et al., 2003; Qin et al., 2005), were also corroborated with effectiveness in improvement in muscle strength and balance. In this study, the knee extension torque of the non-dominant leg in the DG was significantly higher than that in the CG. Moreover, the knee torque of the dominant leg tended to be higher in the DG than in the CG, even though not statistically significant ( $p=$ 0.053). We know that low-impact dance practitioners perform their dance steps by maintaining contact with the ground. These repetitive movements reinforce muscle groups of the lower extremities through the impact of hitting the ground in addition to increasing muscle contractions. We suggest that this model of low-impact dance is a possible reason for the significant difference in the non-dominant leg between the DG and CG. In fact, the above-mentioned stimulations resemble weight-bearing exercises in several studies (Bravo et al., 1996; Kukuljan et al., 2009), which supported the beneficial effects of impact from exercise on muscles.

On the other hand, previous literature (Engels et al., 1998; Hopkins et al., 1990) reported that low-impact dance benefited balance and muscle strength of the lower extremities. From the results of dynamic balance, this study also supports conclusions of the related studies on low-impact dance. However, no significant differences were evident in the static balance of the dominant or non-dominant leg between these two groups. In addition, after associations between knee extension torque and static balance of the dominant and non-dominant legs in the respecttive groups were further analyzed, no significant relationships were evident. As a result, although low-impact dance displayed a positive result on dynamic balance, further studies regarding the influence of low-impact dance on balance are warranted, because the results for static balance seemed counter to the hypothesis of this study.

Several studies indicated that the ROMs of joints in the lower extremities of women and men decrease with age (James \& Parker, 1989; Sepic et al., 1986), and the ROMs of these joints in women, such as the ankles, knees and hips, declined more obviously and faster than those of men (Vandervoort et al., 1992). These negative developments, of reduced ROMs of joints in the lower extremities, are likely to increase the chances of losing one's balance and lead to falls (Mecagni et al., 2000; Vandervoort et al., 1990). Several studies reported that the intervention of a battery of physical activities or exercises improved the ROMs of joints, and those positive changes could contribute to a decline in the incidence of falls (Cao et al., 2007; Katzman et al., 2007). In the current study, in addition to a few ROMs of joints in the non-dominant leg of the DG tending to be higher compared to those of the CG, most ROMs of joints in the dominant leg, ankle inversion, plantiflexion, and dorsiflexion, were significantly higher in the DG than the CG. These results are in agreement with a study by Cao et al., (2007), which supported the positive influence of exercise on ROMs of joints in the lower extremities. We inferred that diverse dance steps, such as side-stepping, walking forward and backward, circling, lifting the legs, tiptoeing with the foot to the front, side, and rear, and raising the heels, were frequently executed with the fixed dominant leg. This bias of utilization is likely to be the reason for the difference between the two groups. On the other hand, although a few movements, such as side-stepping and circling, seem to be useful for the ROM of these joints, no significant difference was found in the ROMs of the hips between the DG and the CG, except for hip external rotation. It is difficult for us to speculate on the reason for this. Accordingly, further studies are needed to explore possible reasons why the ROMs of these joints were higher in the DG than the CG according to the current results. However, maintaining a certain degree of ROMs of lower-extremity joints from low-impact dance is a novel finding in this study, especially of the dominant leg, compared to sedentary counterparts. Studies on older persons reported that maintenance or improvement of the ROM of the lower extremities with exercise can boost the performance of activities of daily living (Alexander et al., 2001; Stanziano et al., 2009). Low-impact dancers enjoy this benefit feature because the ROMs of their lower limbs are superior to those of physically inactive individuals.

\section{Limitations}

A few limitations exist in this study. The data regarding fall cases in this study were not investigated, although the parameters were related to risk factors for falls. In addition, because this study was not an intervention type of experiment, we cannot infer causality from the aforementioned results, such as balance and torque of knee extension. As a result, further studies are warranted to examine associations between falls and related parameters for regular participants of low-impact dance and the comparisons between low-impact dancers and sedentary individuals.

\section{Conclusion}

Regular low-impact dancers showed positive features compared to individuals who were physically inactive, such as significantly higher torque and ROM of the lower extremities. In addition, the balance capacity, especially dynamic balance, was obviously higher in participants of low-impact dance. These promising findings should prompt further direct studies to investigate changes in related parameters and fall cases in the elderly who participate in low-impact dance interventions.

\section{REFERENCES}

Alexander, N. B., Gross, M. M., Medell, J. L., \& Hofmeyer, M. R. (2001). Effects of functional ability and training on chair-rise biomechanics in older adults. The Journals of Gerontology, Series A: Biological Sciences and Medical Sciences, 56, M538-M547. doi:10.1093/gerona/56.9.M538

American College of Sports Medicine (1998). American college of sports medicine position stand: Exercise and physical activity for older adults. Medicine and Science inSports and Exercise, 30, 9921008.

Asikainen, T. M., Kukkonen-Harjula, K., \& Miilunpalo, S. (2004). Exercise for health for early postmenopausal women. Sports Medicine, 34, 753-778. doi:10.2165/00007256-200434110-00004

Bird, M. L., Hill, K., Ball, M., \& Williams, A. D. (2009). Effects of resistance- and flexibility-exercise interventions on balance and re- 
lated measures in older adults. Journal of Aging and Physical Activity, 17, 444-454.

Bocalini, D. S., Serra, A. J., dos Santos, L., Murad, N., \& Levy, R. F. (2009). Strength training preserves the bone mineral density of postmenopausal women without hormone replacement therapy. Journal of Aging and Health, 21, 519-527. doi:10.1177/0898264309332839

Bravo, G., Gauthier, P., Roy, P. M., Payette, H., Gaulin, P., Harvey, M., Péloquin, L., \& Dubois, M. F. (1996). Impact of a 12-month exercise program on the physical and psychological health of osteopenic women. Journal of the American Geriatrics Society, 44, 756-762.

Cao, Z. B., Maeda, A., Shima, N., Kurata, H., \& Nishizono, H. (2007). The effect of a 12-week combined exercise intervention program on physical performance and gait kinematics in community-dwelling elderly women. Journal of Physiological Anthropology, 26, 325-332. doi:10.2114/jpa2.26.325

Carville, S. F., Rutherford, O. M., \& Newham, D. J. (2006). Power output, isometric strength and steadiness in the leg muscles of preand postmenopausal women; the effects of hormone replacement therapy. European Journal of Applied Physiology, 96, 292-298. doi:10.1007/s00421-005-0078-4

Chandler, J. M., Duncan, P. W., Kochersberger, G., \& Studenski, S. (1998). Is lower extremity strength gain associated with improvement in physical performance and disability in frail, communitydwelling elders? Archives of Physical Medicine and Rehabilitation, 79, 24-30. doi:10.1016/S0003-9993(98)90202-7

Dowdy, D. B., Cureton, K. J., DuVal, H. P., \& Ouzts, H. G. (1985). Effects of aerobic dance on physical work capacity cardiovascular function and body composition of middle-aged obese women. Research Quarterly for Exercise and Sport, 56, 227-233.

Engels, H. J., Drouin, J., Zhu, W., \& Kazmierski, J. F. (1998). Effects of low-impact, moderate-intensity exercise training with and without wrist weights on functional capacities and mood states in older adults. Gerontology, 44, 239-244. doi:10.1159/000022018

Götherström, G., Elbornsson, M., Stibrant-Sunnerhagen, K., Bengtsson, B. A., Johannsson, G., \& Svensson, J. (2010). Muscle strength in elderly adults with GH deficiency after 10 years of GH replacement. European Journal of Endocrinology, 163, 207-215. doi:10.1530/EJE-10-0009

Greeves, J. P., Cable, N. T., Reilly, T., \& Kingsland, C. (1999). Changes in muscle strength in women following the menopause: A longitudinal assessment of the efficacy of hormone replacement therapy. Clinical Science, 97, 79-84. doi:10.1042/CS19980406

Hammar, M. L., Lindgren, R., Berg, G. E., Moller, C. G., \& Niklasson, M. K. (1996). Effects of hormonal replacement therapy on the postural balance among postmenopausal women. Obstetrics and Gynecology, 88, 955-960. doi:10.1016/S0029-7844(96)00356-0

Haskell, W. L., Lee, I. M., Pate, R. R., Powell, K. E., Blair, S. N., Franklin, B. A., Macera, C. A., Heath, G. W., Thompson, P. D., \& Bauman, A. (2007). Physical activity and public health: Updated recommendation for adults from the American College of Sports Medicine and the American Heart Association. Medicine and Science in Sports and Exercise, 39, 1423-1434. doi:10.1249/mss.0b013e3180616b27

Hopkins, D. R., Murrah, B., Hoeger, W. W., \& Rhodes, R. C. (1990). Effect of low-impact aerobic dance on the functional fitness of elderly women. The Gerontologist, 30, 189-192. doi:10.1093/geront/30.2.189

Hortoba' gyi, T., Tunnel, D., Moody, J., Beam, S., \& DeVita, P. (2001). Low- or high-intensity strength training partially restores impaired quadriceps force accuracy and steadiness in aged adults. The Journals of Gerontology, Series A: Biological Sciences and Medical Sciences, 56, B38-B47. doi:10.1093/gerona/56.1.B38

Huang, T. T., Yang, L. H., \& Liu, C. Y. (2011). Reducing the fear of falling among community-dwelling elderly adults through cognitive-behavioural strategies and intense Tai Chi exercise: A randomized controlled trial. Journal of Advanced Nursing, 67, 961-971. doi:10.1111/j.1365-2648.2010.05553.x

James, B., \& Parker, A. W. (1989). Active and passive mobility of lower limb joints in elderly men and women. American Journal of Physical Medicine \& Rehabilitation, 68, 162-167. doi:10.1097/00002060-198908000-00002
Janis, L. R. (1990). Aerobic dance survey. A study of high-impact versus low-impact injuries. Journal of the American Podiatric Medical Association, 80, 419-423.

Katzman, W. B., Sellmeyer, D. E., Stewart, A. L., Wanek, L., \& Hamel, K. A. (2007). Changes in flexed posture, musculoskeletal impairments, and physical performance after group exercise in community-dwelling older women. Archives of Physical Medicine and Rehabilitation, 88, 192-199. doi:10.1016/j.apmr.2006.10.033

Kukuljan, S., Nowson, C. A., Sanders, K., \& Daly, R. M. (2009). Effects of resistance exercise and fortified milk on skeletal muscle mass, muscle size, and functional performance in middle-aged and older men: An 18-mo randomized controlled trial. Journal of Applied Physiology, 107, 1864-1873. doi:10.1152/japplphysiol.00392.2009

Macaluso, A., Young, A., Gibb, K. S., Rowe, D. A., \& De Vito, G. (2003). Cycling as a novel approach to resistance training increases muscle strength, power, and selected functional abilities in healthy older women. Journal of Applied Physiology, 95, 2544-2553.

Mecagni, C., Smith, J. P., Roberts, K. E., \& O’Sullivan, S. B. (2000). Balance and ankle range of motion in community-dwelling women aged 64 to 87 years: A correlational study. Physical Therapy, 80, 10041011.

Melzer, I., Benjuya, N., \& Kaplanski, J. (2003). Effects of regular walking on postural stability in the elderly. Gerontology, 49, 240245. doi:10.1159/000070404

Norkin, C. W., \& White, D. J. (1995). Measurement of joint motion (2nd ed.). Philadelphia, FA: Davis.

Qin, L., Choy, W., Leung, K., Leung, P. C., Au, S., Hung, W., Dambacher, M., \& Chan, K. (2005). Beneficial effects of regular Tai Chi exercise on musculoskeletal system. Journal of Bone and Mineral Metabolism, 23, 186-190. doi:10.1007/s00774-004-0559-2

Ricard, M. D., \& Veatch, S. (1990). Comparison of impact forces in high and low impact aerobic dance movements. International Journal of Sport Biomechanics, 6, 67-77.

Ricotti, L., \& Ravaschio, A. (2011). Break dance significantly increases static balance in 9 years-old soccer players. Gait Posture, 33, 462465. doi:10.1016/j.gaitpost.2010.12.026

Roberts, H. (2007). Managing the menopause. British Medical Journal, 334, 736-741. doi:10.1136/bmj.39153.522535.BE

Rubenstein, L. Z. (2006). Falls in older people: Epidemiology, risk factors and strategies for prevention. Age and Ageing, 35, ii37-ii41. doi:10.1093/ageing/afl084

Sepic, S. B., Murray, M. P., Mollinger, L. A., Spurr, G. B., \& Gardner, G. M. (1986). Strength and range of motion in the ankle in two age groups of men and women. American Journal of Physical Medicine, 65, 75-84.

Shigematsu, R., Okura, T., Sakai, T., \& Rantanen, T. (2008). Squarestepping exercise versus strength and balance training for fall risk factors. Aging Clinical and Experimental Research, 20, 19-24.

Shimamoto, H., Adachi, Y., Takahashi, M., \& Tanaka, K. (1998). Low impact aerobic dance as a useful exercise mode for reducing body mass in mildly obese middle-aged women. Journal of Physiological Anthropology, 17, 109-114.

Stanziano, D. C., Roos, B. A., Perry, A. C., Lai, S., \& Signorile, J. F. (2009). The effects of an active-assisted stretching program on functional performance in elderly persons: A pilot study. Clinical Interventions in Aging, 4, 115-120.

Steffen, T. M., Hacker, T. A., \& Mollinger, L. (2002). Age- and gender-related test performance in community-dwelling elderly people: Six-minute walk test, Berg balance scale, timed up \& go test, and gait speeds. Physical Therapy, 82, 128-137.

Vandervoort, A. A., Chesworth, B. M., Cunningham, D. A., Rechnitzer, P. A., Paterson, D. H., \& Koval, J. J. (1992). An outcome measure to quantify passive stiffness of the ankle. Canadian Journal of Public Health, 83, S19-S23.

Vandervoort, A. A., Hill, K., Sandrin, M., \& Vyse, V. M. (1990). Mobility impairment and falling in the elderly. Physiotherapy Canada, 42, 99-107.

Yokoya, T., Demura, S., \& Sato, S. (2008). Fall risk characteristics of the elderly in an exercise class. Journal of Physiological Anthropology, 27, 25-32. doi:10.2114/jpa2.27.25 